\title{
An alginate hydrogel dura mater replacement for use with intracortical electrodes
}

\author{
Elizabeth A. Nunamaker, Daryl R. Kipke \\ Department of Biomedical Engineering, University of Michigan, Ann Arbor, Michigan 48109-2099
}

Received 6 March 2010; revised 2 August 2010; accepted 17 August 2010

Published online 28 September 2010 in Wiley Online Library (wileyonlinelibrary.com). DOI: 10.1002/jbm.b.31733

\begin{abstract}
The collagenous dura mater requires a secure closure following implantation of neural prosthetic devices to avoid complications due to cerebrospinal fluid leakage and infections. Alginate was previously suggested for use as a dural sealant. The liquid application and controllable gelling conditions enable alginate to conform to the unique geometries of a neural prosthetic device and the surrounding dura mater to create a barrier with the external environment. In this study, we evaluated the use of alginate as a method to securely reclose a dural defect and seal around an untethered microscale neural probe in the rabbit model. After 3 days and 3 weeks, the sealing strength of alginate remained eight times greater than normal rabbit intracranial pressure and
\end{abstract}

similar in both the presence and absence of a penetrating neural probe. For time points up to 3 months, there was no significant difference in dura mater fibrosis or thickness between alginate and controls. Application of alginate to a dural defect results in a watertight seal that remains intact while the dura mater reforms. These findings indicate that alginate is an effective tool for sealing around microscale neural probes and suggests broader application as a sealant for larger neural prosthetic devices. (c) 2010 Wiley Periodicals, Inc. J Biomed Mater Res Part B: Appl Biomater 95B: 421-429, 2010.

Key Words: biocompatibility/soft tissue, stability, dura, hydrogel, in vivo

\section{INTRODUCTION}

The use of penetrating neural prosthetic devices in both the research and clinical settings are increasing, necessitating the development of advanced dural sealants and patches. A watertight seal around these devices is imperative to prevent cerebrospinal fluid (CSF) leakage or device failure due to infection. A dural patch also functions to help keep the surface of the brain moist, minimize swelling, and reestablish the barrier to the outside world. A traditional dural defect can be repaired by suturing a sheet of one of various polymers $^{1-5}$ or biologically occurring tissues ${ }^{6-12}$ to the surrounding tissue. Unfortunately, these traditional approaches are not appropriate for sealing around neural prosthetic devices which must project through the dura mater and can have smooth surfaces and unique geometries that prohibit suturing.

An ideal duraplasty material for use with penetrating neural prosthetics must satisfy several design requirements. These include the following: (1) prevention of CSF leakage ${ }^{13-15}$ under increased intracranial pressure (ICP) conditions which can be as high as $23 \mathrm{mmHg}$ in humans following significant brain trauma $\left(2-3\right.$ times normal ICP ${ }^{16}$; (2) the seal with the surrounding tissue should be maintained until the dura mater regrows ${ }^{5,15}$; (3) exhibit mechanical properties similar to natural dura mater ; (4) not induce of a harmful foreign body response ${ }^{17}$; (5) not cause any adhesion formation between the dura mater and underlying cortex, ${ }^{17}$ or prosthetic device; (6) not cause significant changes in tissue morphology or function ${ }^{17}$; (7) easy to use; and (8) not cause abnormal neuronal signaling or seizures. ${ }^{18}$

Historically, a variety of materials have been used for duraplasty but many have had deleterious effects, including leaks, ${ }^{14}$ seizure activity, ${ }^{19}$ hematomas, ${ }^{20}$ Creutzfeldt-Jakob disease, $^{21,22}$ and significant inflammatory response. ${ }^{1,2,13}$ More recently, the feasibility of using hydrogels to repair dural defects has been demonstrated in animal models. Specifically, polyethylene glycol has demonstrated excellent sealing capabilities and biocompatibility when used as a dural sealant. ${ }^{23,24}$ Preliminary studies with alginate show similar promise due to the long-term biocompatibility and mild reaction conditions that allow hydrogel crosslinking while in direct contact with the surrounding meningeal and neural tissues. ${ }^{25,26}$ Additionally, alginate has been shown to not cause seizure activity in rats ${ }^{25}$ or a significant inflammatory response, ${ }^{27-30}$ problems which have hindered the development of previous polymer-based dural sealants. ${ }^{19,31,32}$

There have been relatively few different approaches employed to reseal a brain that has been implanted with a penetrating neural prosthetic device. Gelfoam ${ }^{\circledR}$, a hemostatic absorbable gelatin scaffold, and Kwik-sil, a silicone silastic polymer, have been commonly used. ${ }^{33-37}$ Gelfoam $^{\circledR}$ has a very mild inflammatory response which leaves little scaring as the material degrades over 6 weeks. Silicone has been shown to cause hematomas when used as a duraplasty material in humans. ${ }^{20,38,39}$ Maynard et al. discussed a combination approach which employed a subdural Teflon sheet 
above the electrode array, and an epidurally sutured sheet of Preclude ${ }^{\circledR}{ }^{40}$ While this approach prevented adhesion formation between the dura mater and electrode array in cats, ${ }^{40}$ Preclude ${ }^{\circledR}$ has been shown to cause osseous metaplasia after 6 months in rabbits. ${ }^{1}$ Additionally, both Teflon and Preclude ${ }^{\circledR}$ require suture to hold them in place, creating additional holes in the repaired dura mater and potential for CSF leakage.

More recently, alginate has been described for duraplasty alone or in combination with penetrating neural prosthetic devices. ${ }^{26,41,42}$ Applied as a viscous liquid, alginate does not require sutures to approximate the tissue or hold the dural graft in place. This also allows alginate to form to any shape, creating a seal around the unique geometries of microelectrodes. Alginate's ease of use, biocompatibility, and sealing strength when used alone for duraplasty suggest it is a superior candidate for resealing of the dura mater in the presence of penetrating neural prosthetic devices.

The goals of this study were to investigate the following: (1) the duraplasty sealing strength of alginate crosslinked with $\mathrm{CaCO}_{3}$, (2) changes in tissue histopathology, and (3) the sealing strength of alginate in the presence of a penetrating microscale neural probe in the context of a rabbit duraplasty model. We sought to identify the interplay of alginate degradation and tissue regrowth over time to understand how these properties influence the sealing capabilities of an alginate dural replacement patch. Additionally, we wanted to identify tissue meningeal regrowth around the probes over time to understand how these properties potentially influence the sealing capabilities of an alginate dural sealant in the presence of penetrating neural prosthetic devices. Ultimately, our goal was to demonstrate a watertight seal around a penetrating neural prosthetic device and the ability of the hydrogel patch to maintain a barrier against the external environment over time. The results indicate that alginate is a viable dural replacement material and is able to maintain a watertight barrier for at least 3 months.

\section{MATERIALS AND METHODS}

\section{Hydrogel preparation}

Hydrogel components, alginate and $\mathrm{CaCO}_{3}$, were prepared and sterilized separately before use. Ultra pure sodium alginate (43 mPas) was acquired from Novamatrix (Pronova UP LVG, Drammen, Norway). Alginate was ethylene oxide gas sterilized and a 1.95 wt \% solution was made in sterile water. The alginate solution was stored in sterile $1 \mathrm{~mL}$ aliquots for later use. $\mathrm{CaCO}_{3}$ (Sigma, St. Louis, MO) was weighed out into $10 \mathrm{mg}$ samples and ethylene oxide gas sterilized.

The alginate and $\mathrm{CaCO}_{3}$ were mixed thoroughly before application to the dural defect, resulting in a $100 \mathrm{mM}$ $\mathrm{CaCO}_{3}$ concentration. Glucono- $\delta$-lactone (GDL) (Sigma, St. Louis, MO) was prepared into $1 M$ solution in sterile water and sterile-filtered immediately before use. The sterile GDL solution was added to the alginate: $\mathrm{CaCO}_{3}$ solution at a final GDL concentration of $80 \mathrm{~m} M$ and mixed vigorously. The resulting three component mixture was allowed to sit for
10 min to increase solution viscosity to $\sim 400 \mathrm{cP}^{41}$ thereby improving site-specific application of the hydrogel to the dural defect and microscale neural probe. A volume of 20 $\mu \mathrm{L}$ was applied to the dural defect with a pipette.

\section{Neural probe}

The dummy neural probes were microfabricated from SU-8 and parylene-C, resulting in a transparent probe (Figure 1). SU-8, a photoepoxy that is commonly used as a photoresist in microfabrication processes, was used as the backbone of the probe to provide rigidity during implantation. ParyleneC was deposited on the SU-8 backbone at room temperature to create the outer structures and a biocompatible isolation barrier. Parylene-C has been employed as a biocompatible insulating material on electrodes for many years and has been shown to have no significant effect on the arachnoid and pia mater after 16 weeks of implantation. ${ }^{43,44}$ These materials were used in the probe construction because they could be left in the tissue during sectioning to avoid disruption of the alginate:probe:dura mater interfaces.

\section{Animals and groupings}

New Zealand white rabbits (2.8-4.5 kg) were utilized (Harlan, Indianapolis, IN) to test duraplasty sealing strength and biocompatibility of alginate alone and in the presence of a penetrating microscale neural probe. In addition to alginate, a hemostatic, absorbable gelatin scaffold (Gelfoam ${ }^{\circledR}$, Pharmacia \& Upjohn, Kalamazoo, MI) was also investigated alone. Gelfoam ${ }^{\circledR}$ was chosen because it is commonly used in combination with penetrating neural prosthetic devices. ${ }^{36,37}$ Twenty-four rabbits were randomly assigned to an alginate or Gelfoam ${ }^{\circledR}$ test group, before surgery, for experimental endpoints of 3 days, 3 weeks, or 3 months. Each experimental condition and endpoint group consisted of four animals. Upon completion of the initial experiments, six additional rabbits were implanted with a neural probe before application of the alginate for experimental endpoints of 3 days or 3 weeks (three animals each). All rabbits additionally underwent a surgical control procedure. Every animal was used for both identification of sealing strength and histology. All procedures were approved by the University of Michigan Committee on Use and Care of Animals.

\section{Surgical procedure}

Rabbits were initially anesthetized with an intramuscular injection of ketamine $(35 \mathrm{mg} / \mathrm{kg}$ ) and xylazine $(5 \mathrm{mg} / \mathrm{kg})$ followed by intubation for anesthesia maintenance with $2 \%$ isoflurane. All animals were given a preoperative dose of buprenorphine $(0.05 \mathrm{mg} / \mathrm{kg})$ to facilitate pain management immediately following surgery. The scalp was opened with a single midline incision and retracted, followed by the creation of bilateral, $1 \mathrm{~cm}$ diameter, calvarial defects posterior to bregma. One defect was used for the sealing strength experiment and the other one served as a control for the tissue effects of bone removal. A 2-mm diameter duratomy was performed in the middle of one of the calvarial defects. For the alginate animals, alginate $(20 \mu \mathrm{L})$ was applied as a 


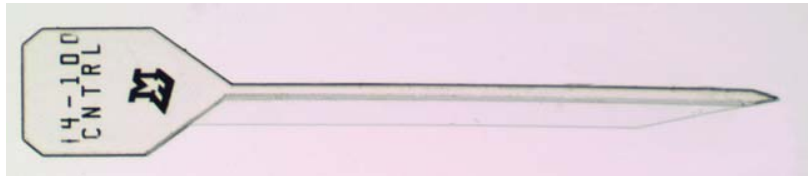

FIGURE 1. A photomicrograph of the parylene-C neural dummy probe with a SU-8 core. The probe is $3 \mathrm{~mm}$ long from the tip to top of head and the shank width tapered from $170 \mu \mathrm{m}$ wide to form the tip. The main structure is $43 \mu \mathrm{m}$ thick, but the lateral shank structure is only 5 $\mu \mathrm{m}$ thick. The probe has no recording sites and is not tethered to a cable. [Color figure can be viewed in the online issue, which is available at wileyonlinelibrary.com.]

highly viscous solution to the dural defect with a pipette. In Gelfoam $^{\circledR}$ animals, Gelfoam was applied using an in-lay technique, securing the Gelfoam ${ }^{\circledR}$ under the edges of the dura mater surrounding the dural defect. ${ }^{45}$ For the alginate with a probe condition, an untethered parylene-C neural probe was placed centrally in the dural defect and subsequently repaired with alginate as described earlier. After the dura mater was repaired with alginate or Gelfoam ${ }^{\circledR}$, both calvarial defects were covered with a thin sheet of Teflon and covered with a bone cement headcap (TemPhase, sdsKerr, Switzerland) secured to an anteriorly positioned bone screw for structural rigidity. The skin was closed over the cement with sutures and skin glue. All animals were given buprenorphine $(0.05 \mathrm{mg} / \mathrm{kg})$ postoperatively twice daily for 2 days following surgery to manage postoperative pain.

\section{Sealing strength of dural patch}

The ability of the dural patch to maintain a watertight seal was tested at 3 days, 3 weeks, or 3 months postsurgery as previously designated. To test the sealing strength, the rabbits were anesthetized as described for the initial surgery, but were subsequently placed on mechanical ventilation with $2 \%$ isoflurane for maintenance due to the prolonged nature of the procedure. The rabbit's midline incision was reopened and continued caudally, exposing the neck musculature. The muscle tissue was removed to expose the occipital bones and the first cervical vertebra to yield clear access to the cisterna magna. The bone cement headcap was displaced to expose the calvarial defects and the duraplasty site. Blood clots and bone tissue were carefully removed from the calvarial defects as needed for clear visualization of the duraplasty site containing the neural probe. A catheter was then inserted into the cisterna magna and glued with a cyanoacrylate adhesive into place to prevent leaking at the dura mater:catheter interface. Correct catheter location was verified by rapid filling of the catheter with CSF. The catheter was attached to a syringe pump (Model 554155, Harvard Apparatus, Holliston, MA) and pressure transducer (PX26-005DV, Omega, Stamford, CT) via intravenous tubing.

The sealing strength was tested using methods adapted by Filippi et al. ${ }^{7}$ Artificial cerebrospinal fluid (ACSF) with $0.05 \%$ carboxyfluorescein (Sigma, St. Louis, MO) was infused at $0.05 \mathrm{~mL} / \mathrm{min}$ under the control of a custom LabView (LabView 7.1, National Instruments, Austin, TX) module that controlled the syringe pump and recorded the infusion pressure. This infusion rate was chosen because it is greater than the normal rate of CSF formation for rabbits $\left(0.01 \mathrm{~mL} / \mathrm{min}^{46}\right)$ and insured accumulation of fluid volume to continually increase ICP. Both the infusion volume and pressure were monitored continuously by the LabView module. The duraplasty/probe site was monitored with a fluorescent stereomicroscope (MZ8, Leica, Switzerland) to identify fluorescing on the surface of the brain and around the neural probe and alginate hydrogel (Figure 2). Images were collected with a CCD camera (SPOT 1.4.0, Diagnostic Instruments, Sterling Heights, MI). ACSF with carboxyfluorescein was infused until leakage was detected visually or until a pressure of $45 \mathrm{mmHg}$ was exceeded. The leak pressure was defined as the infusion pressure at which fluorescence was first detected on the surface of the alginate or the surrounding dura mater. If the pressure exceeded 45 $\mathrm{mmHg}$ without rupture, the sealing strength was recorded as $45 \mathrm{mmHg}$ and the experiment was terminated. The results for sealing strength were analyzed by a one-tailed Mann-Whitney nonparametric $t$-test to identify significance between time points.
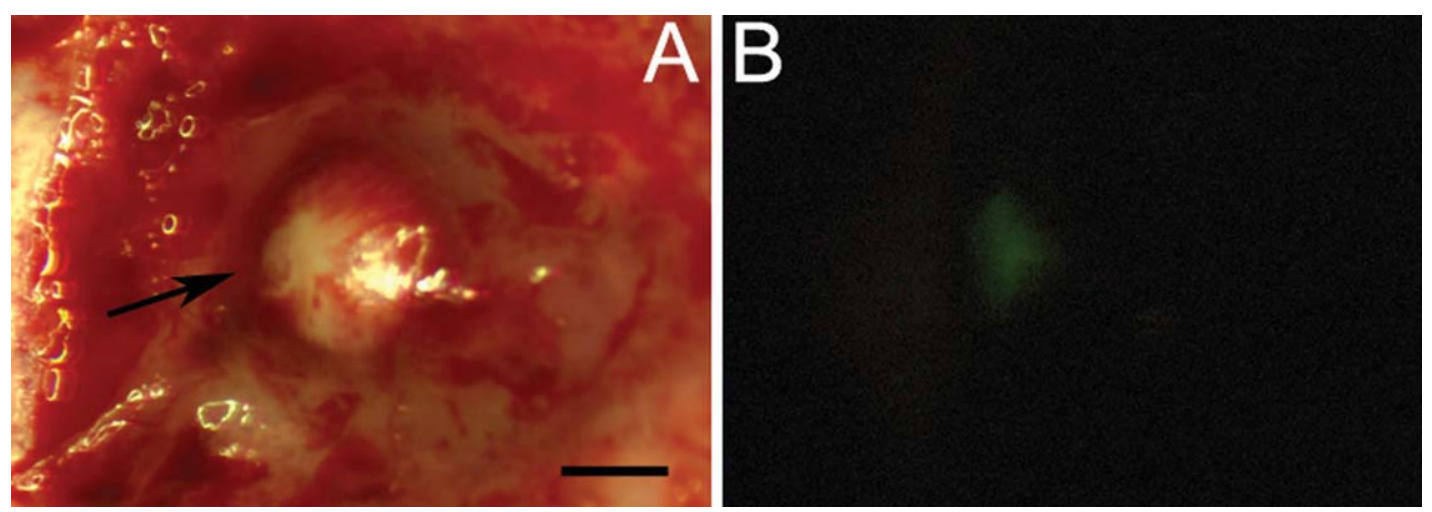

FIGURE 2. Visual detection of sealing strength after 3 weeks. A: A focal bump is seen where the dura mater has grown above the alginate and neural probe. The location of the seal break is indicated by an arrow. The scale bar represents $2 \mathrm{~mm}$ in both micrographs. B: The fluorescence micrograph indicates a leak. The leak corresponds to the left edge of the duraplasty indicated by an arrow in A. [Color figure can be viewed in the online issue, which is available at wileyonlinelibrary.com.] 


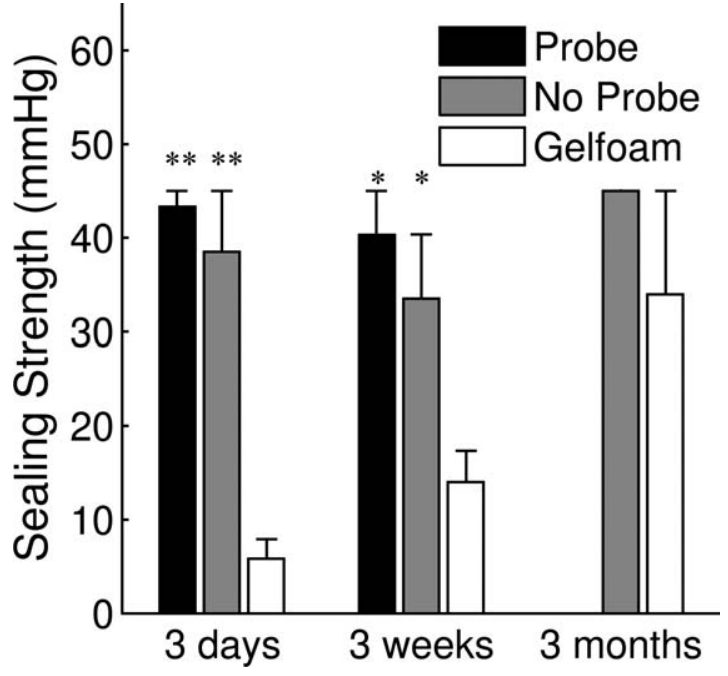

FIGURE 3. Duraplasty sealing strength was maintained over time for alginate. Significance versus Gelfoam ${ }^{\circledR}$ at the comparable endpoint is reported (* indicates $p<0.05, * *$ indicates $p<0.01$ ). $n=4$ for 3 days and 3 weeks, and $n=2$ for 3 months for alginate alone and Gelfoam ${ }^{\circledast}$. $n=3$ for all time points for alginate with probe.

\section{Tissue response}

Upon completion of the sealing strength measurement, the rabbit was exsanguinated under anesthesia via cardiac infusion of $1 \mathrm{~L}$ of phosphate buffered saline followed by $1 \mathrm{~L} 4 \%$ paraformaldehyde. After perfusion fixation was complete, the brain was explanted in individual left and right hemispheres, maintaining anatomical position of the tissues, and postfixed in Bouin's Fixative for $24 \mathrm{~h}$. The samples were dehydrated in a series of ethanol dilution rinses and paraffin embedded. Serial sections, $6 \mu \mathrm{m}$ thick, were taken over the entire region of interest and stained with toluidine blue (TB), hematoxylin and eosin (HE), or Masson's trichrome (MT). TB allowed for visualization of alginate within the sample by staining the alginate purple. HE was used to identify the presence of immune and inflammatory response cells and level of fibrosis. MT clearly identified the meningeal tissue through the bright blue staining of collagen.

The level of fibrosis was determined using a predetermined scale. One HE slide from the duraplasty site (alginate or Gelfoam ${ }^{\circledR}$ ) and control tissue of each animal was analyzed by three blinded observers and given a score $(0-3)$. The scoring levels indicating increasing levels of fibrosis are as follows: (0) low fibroblast density in all meningeal tissue, similar to naïve tissue; (1) increased pial fibroblast density but normal density in dura and arachnoid mater; (2) increased fibroblast density in all layers of the meningeal tissue; (3) dense fibroblast density in dura mater. The scores reported by the blinded observers were combined to calculate the average and standard error for each condition ( 3 days, 3 weeks, and 3 months for alginate, Gelfoam ${ }^{\circledR}$, and control tissue).

Dura mater thickness was determined by measuring the width of collagen in one MT stained slide from the duraplasty site or control tissue of each animal. The collagen thickness was measured in four different places for each sample and averaged resulting in a single thickness for each sample. The thicknesses for a condition were combined to calculate the average and standard error for each condition (3 days, 3 weeks, and 3 months for alginate, Gelfoam ${ }^{\circledR}$, and control tissue).

\section{RESULTS}

\section{Macroscopic findings}

The calvarial defects of all rabbits were reclosed by the 3 month time point. On day 3 , the calvarial defects were filled with blood clots that could be easily removed to visualize the alginate and neural probe. After 3 weeks, the blood clots were replaced by a thin membrane that covered the calvarial defects. Although the neural probe could be clearly identified surrounded by alginate on day 3, after 3 weeks, the dura mater had grown over the alginate and neural probe, impeding visualization [Figure 2(A)]. By 3 months, the calvarial defects had completely filled in with new bone tissue. Significant adhesions between the new bone and underlying dura after 3 months was found on the duraplasty side in three of four Gelfoam ${ }^{\circledR}$ animals, but only one of four alginate animals. No adhesions were detected in the control calvarial defects.

\section{Sealing strength of dural patch}

Alginate demonstrated stronger sealing strength than Gelfoam $^{\circledR}$ (Figure 3 and Table 1). ACSF leakage was detected visually as seen in Figure 2(B). On day 3, alginate withstood significantly greater pressure than Gelfoam ${ }^{\circledR}(p<0.01)$. After 3 weeks, alginate continued to withstand significantly greater pressure than Gelfoam ${ }^{\circledR}(p<0.05)$. At the 3-month time point, only two animals were tested per condition due to adhesions or microtears of the dura mater due to bone removal. The difference between the two materials was not significant at this time point $(p=0.34)$, although neither of the alginate animals exhibited rupture whereas only one Gelfoam $^{\circledR}$ animal did not exhibit rupture. No significant difference in alginate's sealing strength was detected between the three time points $(p=0.49)$. Gelfoam ${ }^{\circledR}$, however, did exhibit a significant increase in sealing strength over time (0.31 mmHg/day, $p<0.01$ ).

Alginate demonstrated excellent sealing capabilities in the presence of the microscale neural probe (Figure 3 and Table 1). On day 3, alginate withstood similar pressures in the presence or absence of a neural probe. After 3 weeks, alginate continued to withstand similar pressures in the

TABLE I. The Sealing Strength of Alginate and Gelfoam ${ }^{\circledR}$

\begin{tabular}{lccc}
\hline & 3 Days & 3 Weeks & 3 Months \\
\hline Gelfoam $^{\circledR}$ & $5.83 \pm 2.09$ & $14.01 \pm 3.34$ & $33.98 \pm 11.03$ \\
Alginate alone & $38.50 \pm 6.51^{* *}$ & $33.52 \pm 6.85^{*}$ & $45.00 \pm 0.00$ \\
$\begin{array}{l}\text { Alginate } \\
\quad \text { with probe }\end{array}$ & $43.33 \pm 1.67^{* *}$ & $40.32 \pm 4.68^{*}$ & Not tested \\
& & &
\end{tabular}

Average pressures are reported in $\mathrm{mmHg} \pm$ standard error. Significance versus Gelfoam ${ }^{\circledast}$ at the comparable endpoint is reported (* indicates $p<0.05, * *$ indicates $p<0.01$ ). $n=4$ for 3 days and 3 weeks, and $n=2$ for 3 months for alginate alone and Gelfoam ${ }^{\circledR}$. $n=$ 3 for all time points for alginate with probe. 


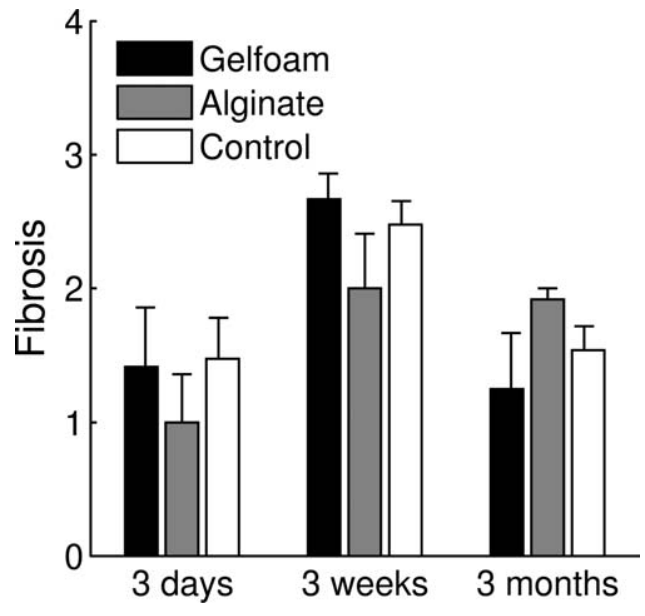

FIGURE 4. Tissue fibrosis over time. There was no significant difference in the tissue fibrosis due to either alginate or Gelfoam ${ }^{\circledR}$ compared with the time-matched control. Average scores are reported \pm standard error, $n=4$ for alginate and Gelfoam ${ }^{\circledR}$, and $n=8$ for control.

presence or absence of a neural probe. There was no significant difference in the sealing strength between alginate alone or in the presence of a dummy probe at either time point $(p>0.50)$. Additionally, there was no significant difference in the sealing strength between the two time points in the presence of the microscale neural probe $(p=0.50)$.

\section{Tissue response}

No significant inflammatory response was seen for either alginate or Gelfoam ${ }^{\circledR}$. Changes in the tissue over time for both experimental conditions are similar to that for control dura mater.

Three days after duraplasty, both alginate and Gelfoam ${ }^{\circledR}$ were seen in close association with the underlying cortex and surrounding dura mater. On both the control side and test condition side (alginate or Gelfoam ${ }^{\circledR}$ ), there were erythrocytes present and the pia mater appeared thickened due to a layer of fibroblast-like cells and an increased macrophage density. No significant increase in the fibroblast density (Figure 4 and Table 2) or thickening of the dura mater (Figure 5 and Table 3) was detected above the normal range at the 3 day time point. Dura mater repair was evident in both test conditions at the 3 week time point. New dura mater was present both underneath and above the alginate patch. Gelfoam ${ }^{\circledR}$ was surrounded by newly formed dura mater and infiltrated with fibroblasts. All conditions

TABLE II. Fibrosis Score

\begin{tabular}{lccc}
\hline & 3 Days & 3 Weeks & 3 Months \\
\hline Gelfoam $^{\circledR}$ & $1.41 \pm 0.43$ & $2.67 \pm 0.19$ & $1.25 \pm 0.42$ \\
Alginate alone & $1.00 \pm 0.36$ & $2.00 \pm 0.41$ & $1.92 \pm 0.08$ \\
Control & $1.48 \pm 0.31$ & $2.48 \pm 0.18$ & $1.54 \pm 0.18$ \\
\hline
\end{tabular}

Average scores are reported \pm standard error, $n=4$ for alginate and Gelfoam ${ }^{\circledR}$, and $n=8$ for control.

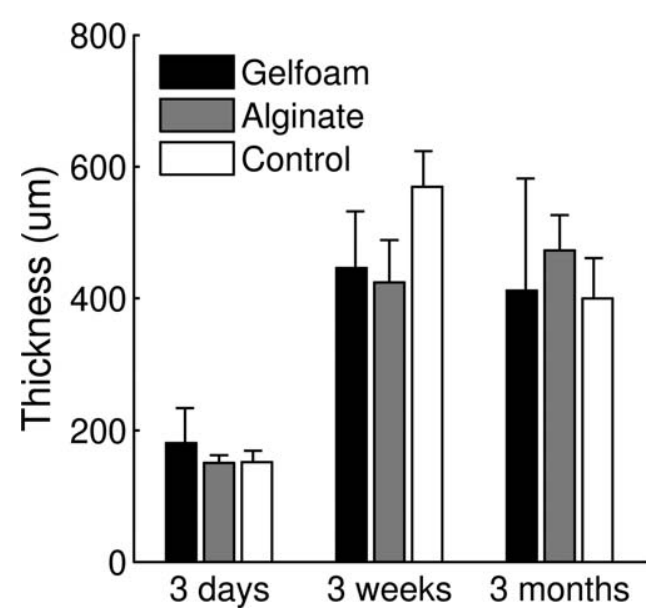

FIGURE 5. Dura thickness increased for all conditions (alginate, Gelfoam $^{(}$, and control) but there were no significant differences between the conditions. $n=4$ for alginate and Gelfoam ${ }^{\circledR}, n=8$ for control.

(alginate, Gelfoam ${ }^{\circledR}$, and control) demonstrated an overall increase in fibroblast density in all meningeal layers but there was no significant difference between the conditions ( $p=0.83$ and 0.40 for 3 day and 3 week, respectively). Dural thickness increased significantly for all conditions between day 3 and 3 weeks $(p<0.05)$ but there was no significant difference between conditions $(p=0.73$ and 0.24 for 3 day and 3 week, respectively).

No evidence of the dura mater repair patch (alginate or Gelfoam ${ }^{\circledR}$ ) remained at the 3 month time point. All conditions (alginate, Gelfoam ${ }^{\circledR}$, and control) showed evidence of low-grade dural ossification on the newly formed and surrounding dura mater but this finding was only focal to the region of the calvarial defect. Granulation tissue could also be seen at this time point. Distal dura mater appeared of normal thickness and fibroblast density. In the region of the calvarial defects and duraplasty, the level of fibrosis decreased for both Gelfoam ${ }^{\circledR}$ and control but remained relatively unchanged for alginate (Figure 4 and Table 2). The thickness of the dura mater was similar in thickness to the 3 week time point, and remained significantly increased over the 3 day time point ( $p<0.05$, Figure 5 and Table 3). Paralleling the level of fibrosis, the dural thickness increase was isolated to the region of the calvarial defect and rapidly returned to baseline levels. No significant difference in fibrosis level $(p=0.09)$ or dura mater thickness $(p=0.64)$ existed between the conditions at the 3 month time point.

TABLE III. Dura Mater Thickness

\begin{tabular}{lccc}
\hline & 3 Days & 3 Weeks & 3 Months \\
\hline Gelfoam $^{\circledR}$ & $180.65 \pm 53.28$ & $445.87 \pm 85.96$ & $411.57 \pm 170.22$ \\
$\begin{array}{c}\text { Alginate } \\
\text { alone }\end{array}$ & $150.58 \pm 11.48$ & $423.96 \pm 64.50$ & $472.61 \pm 53.84$ \\
Control & $151.68 \pm 17.39$ & $569.20 \pm 54.35$ & $399.61 \pm 61.34$ \\
\hline
\end{tabular}

Average thicknesses are reported in um \pm standard error, $n=4$ for alginate and Gelfoam ${ }^{\circledR}$, and $n=8$ for control. 

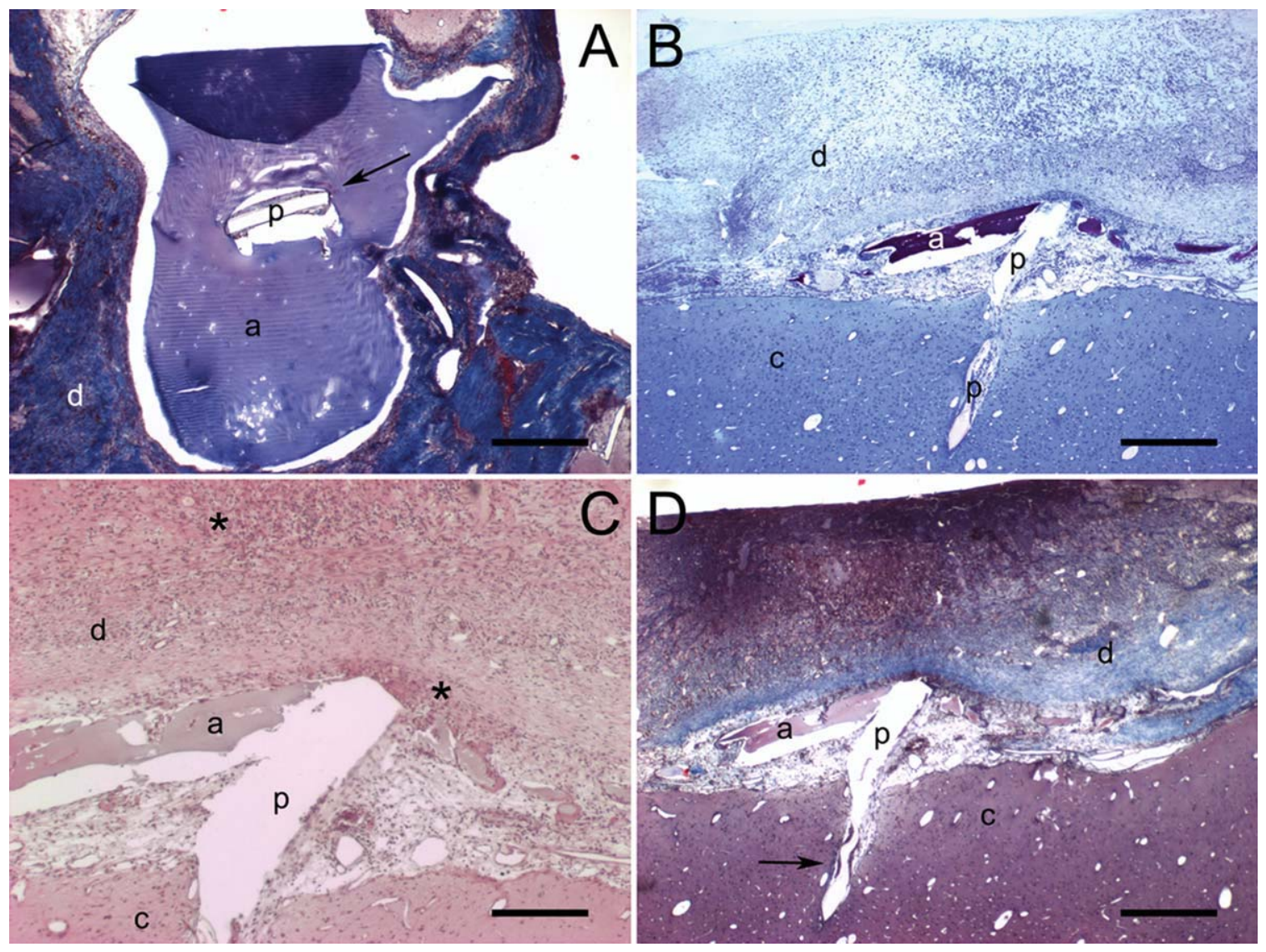

FIGURE 6. Tissue response to alginate and parylene-C probe after 3 weeks. A: The probe (arrow) is seen in the middle of the micrograph surrounding by alginate. The alginate has pulled away from both the tissue and probe due to dehydration of the sample during preparation. MT staining allows visualization of the dura mater (blue) around the outer edge of the alginate (purple). The bar represents $400 \mu \mathrm{m}$. B: Alginate stains bright purple with TB. Dura mater has grown above both the probe and the alginate patch. The bar represents $400 \mu \mathrm{m}$. C: The HE stained section shows the increased fibroblast density in all layers of the meningeal tissue indicated by *. The bar represents $250 \mu \mathrm{m}$. D: The dura mater grew above the implanted probe but the new dura mater is not fully formed as indicated by the lack of blue staining of collagen above the probe. In this MT stained section, a $10 \mu \mathrm{m}$ thick layer of collagen can be seen following the shank of the probe as it projects through the pia mater into cortex (indicated by arrow). The bar represents $400 \mu \mathrm{m}$. In all micrographs: p, probe; a, alginate; c, cortex; and d, dura mater. [Color figure can be viewed in the online issue, which is available at wileyonlinelibrary.com.]

Alginate remained immediately adjacent to the surface of the neural probe up to 3 weeks. Three days after implantation of the neural probe and alginate dura mater repair, the alginate was seen in close association with the underlying cortex, surrounding dura mater, and the neural probe (not shown). Extensive dura mater repair was evident at the 3 week time point (Figure 6). There was an overall increase in fibroblast density in all meningeal layers compared with the 3 day findings, and macrophages remained present around the probe and alginate at 3 weeks [Figure $6(\mathrm{C})]$. The increased fibrosis was also detected in the control dura mater. New, thickened dura mater exhibiting granulation grew above the alginate and neural probe to a thickness of $486.99 \pm 148.54 \mu \mathrm{m}$, and there was evidence of collagen production. The brain cortex appeared normal but a mild gliosis was present at the pial interface. The pia mater was also detectable following the probe shank into the cortical tissue creating a thin layer of collagen between the parylene-C probe and neural tissue [Figure 6(D)].

\section{DISCUSSION}

To investigate the use of alginate as a sealant around penetrating neural prosthetic devices, we identified the sealing strength and biological response in the rabbit model. Application of alginate to a $2 \mathrm{~mm}$ dural defect containing a parylene-C intracortical neural dummy probe resulted in a watertight seal around that probe, capable of withstanding intracranial pressure elevated eight times over the normal rabbit range. The dura mater reformed around the head of the neural probe by 3 weeks, replacing the degrading alginate. The results described herein indicate that alginate is a suitable and desirable material for reestablishing a watertight barrier and allowing the dura mater to regrow in the presence of penetrating neural prosthetic devices. This is the first study that quantitatively identifies the strength of a seal around an implanted neural prosthetic device.

Alginate demonstrated excellent sealing properties. A possible explanation for the sealing strength of alginate is surface tension between the edge of the dural defect and 
probe and the alginate. Using the cisterna magna infusion method adapted by Filippi et al., ${ }^{7}$ alginate was found to seal as well as other commonly used duraplasty materials and additionally maintain a watertight seal around the neural probe that remained stable over time. This sealing strength is comparable to other clinically used duraplasty materials that close dural defects with no penetrating device.,14,15 There was also no decrease in sealing strength due to the presence of a neural probe. Furthermore, alginate does not require suture or additional sealing with fibrin glue to achieve a watertight seal around a neural probe. Together these results indicate the advantages of alginate over other approaches and satisfy the aforementioned design requirements: 1,2 , and 7.

An alginate dural patch retains a watertight seal over time. Similar to Tutoplast dura, a solvent-dried cadaverous human dura mater, the sealing strength decreased slightly but not significantly between 3 days and 3 weeks. ${ }^{7}$ For the alginate patch, this is possibly due to the slow degradation of alginate before complete reformation of the surrounding dura mater. Furthermore, the newly formed dura mater may not be as strong as the original tissue. However, the sealing strength was not significantly lower than the 3 day or 3 month time point, indicating that it still provides a watertight seal with the surrounding dura mater.

The alginate dural patch slowly degraded over time while new dura mater grew above the parylene-C neural probe. Histological investigation revealed that the dura mater had reformed above the alginate and neural probe by the 3 week time point, but the collagen staining was not as dense as naïve tissue. Despite this, the alginate patch was able to maintain ICP eight times greater than normal pressure for the rabbit. Because of the degradation of the alginate patch, further investigation is necessary to determine the sealing strength of alginate used to seal larger penetrating devices such as deep brain stimulating electrodes and fluid shunts. These initial results are very positive however, and support the continued use of alginate to seal around neural prosthetic devices.

While this study included data from the dural patches at 3 months postduraplasty, we did not evaluate the alginate dural patch in combination with the neural probe at this time point. The initial experiments using alginate alone showed that the alginate was fully degraded by the 3 month time point. This finding indicates that the 3 month alginateprobe data would not be indicative of the sealing strength of alginate, but rather the strength of the newly formed dura mater. While potentially interesting, this data is not expected to be significantly different than that if no probe was present, and therefore, in order to minimize the use of animals, we omitted these treatments from the experimental design.

These results for alginate are very similar to those for another hydrogel used for dural repair, polyethylene glycol. Previously, Preul et al. demonstrated that polyethylene glycol could be successfully applied to a $2 \mathrm{~mm}$ dural defect in the canine model to generate a watertight seal. ${ }^{15,24}$ Despite the use of suture to loosely approximate the dura mater in the previous study, ${ }^{15}$ no obvious differences apparent between the sealing strength of alginate and polyethylene glycol. Similar to alginate, the sealing strength of polyethylene glycol slightly decreased over time, but both hydrogels were able to maintain a watertight barrier over all tested time points. To date, polyethylene glycol has not been tested for its sealing capabilities in the presence of a neural prosthetic device.

The tissue response to alginate and Gelfoam ${ }^{\circledR}$ was very mild. Typically, granulation tissue is found overlying the dura mater following removal of the overlying calvarium. ${ }^{47}$ There was evidence of granulation tissue on the surface of the dura mater at the 3 month time point, at which point, extensive bone tissue remodeling had occurred in both control and experimental calvarial defects. Because of the intimate relationship between dura mater and calvarium, this development of granulation tissue is likely a natural response to calvarial regeneration and remodeling. ${ }^{48}$ The bone healing is probably also responsible for the low-grade ossification seen at the 3 month time point in all dura mater samples from the calvarial defect region. Unfortunately, the relationship between the calvarium and dura mater during the healing process is not fully understood and may also contribute to the level of fibrosis and thickness of the dura mater over time. ${ }^{49}$

The level of fibrosis seen in all three conditions peaked at the 3 week time point and then decreased slightly by the 3 month time point. Because there is no difference in fibrosis between the conditions at any given time point, the fibrotic response is most likely due to the removal of the overlying calvarium and not a response to the alginate or Gelfoam $^{\circledR}$. The peak of the fibrotic response at 3 weeks also represents only a mild reaction that transitions into a lowgrade chronic fibrotic response of the tissue. ${ }^{50}$

At all three time points, dura mater thickness changes were not significantly different between repaired dura mater and control dura mater. Neither alginate nor Gelfoam $^{\circledR}$ contributed to the increases in dural thickness seen in this study. Additionally, dura mater thickness for alginate and a neural probe were similar to the alginate treatment alone and determined to not have a significant effect. The biggest contributing factor was opening the calvarium and allowing the bone to heal. Hopper et al. reported similar dural thickening in rabbits receiving calvarial bone grafts that were exposed to the underlying dura mater. ${ }^{49}$ This same study also showed that a thin silicone isolation layer between the dura mater and bone graft resulted in significantly lower dural thickness increases. ${ }^{49}$ This suggests that dural thickening increases for repaired dura could be controlled via isolation of the dura mater from the overlying bone or calvarial defect and supports our previous suggestion to reposition the bone flap in the calvarial defect.

Untethered neural probes were used in this study to simplify the experimental setup. Although a tethered probe would offer a realistic condition, it would likely impede the stability of the alginate:probe:tissue interface during removal of the bone cement headcap. We surmised that this had potential for destabilizing these interfaces during preparation 
for the sealing strength test, which would yield lower sealing strength values than were actually occurring. For these reasons, we chose to pursue an untethered neural probe approach for this initial study. The high sealing strength values that we were able to measure in the short-term study (3 days) suggest that the alginate can maintain a watertight seal around the probe and are therefore expected to perform the same way in the presence of a tethering cable.

Because the alginate was still present around the neural probe after 3 weeks, it is difficult to predict with certainty if the dura mater would grow to become immediately adjacent to the probe to maintain the seal on its own. Histological analysis revealed meningeal tissue following along the shank as it penetrated into the cerebral cortex. Kim et al. also found evidence of meningeal cells around their large hollow fiber probes and suggested that materials in chronic contact with meningeal tissue may serve as a bridging substrate for the attachment, migration, and colonization of meningeal-derived fibroblasts. ${ }^{51}$ This suggests that the dura mater will eventually grow to develop a close contact with the neural probe as the alginate degrades, satisfying the aforementioned design requirements 4 and 6 .

\section{CONCLUSIONS}

The use of an alginate hydrogel to seal around penetrating neural prosthetic devices has many advantages over other duraplasty methods. Here, we demonstrated that it can securely withstand increased ICP levels when used to seal around a penetrating microscale neural probe. As a single material, it is less cumbersome than suturing a patch around the probe followed by sealing with fibrin glue or similar material. Applied as a liquid, the alginate hydrogel can mold to the unique contours of the tissue and prosthetic device to create a watertight seal upon gelation. The result of these synergistic properties is a novel dural sealant with unique utility, facilitating an enhanced interface with the surrounding meninges and providing a method to isolate the central nervous system after implantation of neural prosthetic devices.

\section{ACKNOWLEDGMENTS}

The authors gratefully thank Gail Rising and Michael Charters for skillful technical assistance, John Seymour for providing microscale neural dummy probes, and Dr. Ralph Lydic for insightful discussion.

\section{REFERENCES}

1. Barbolt TA, Odin M, Leger M, Kangas L, Hoiste J, Liu SH. Biocompatibility evaluation of dura mater substitutes in an animal model. Neurol Res 2001;23:813-820.

2. Collins RL, Christiansen D, Zazanis GA, Silver FH. Use of collagen film as a dural substitute: Preliminary animal studies. J Biomed Mater Res 1991;25:267-276.

3. Lee JF, Odom GL, Tindall GT. Experimental evaluation of siliconecoated dacron and collagen fabric-film laminate as dural substitutes. J Neurosurg 1967;27:558-564.

4. Vinas FC, Ferris D, Kupsky WJ, Dujovny M. Evaluation of expanded polytetrafluoroethylene (ePTFE) versus polydioxanone (PDS) for the repair of dura mater defects. Neurol Res 1999;21: 262-268.
5. Yamada K, Miyamoto S, Nagata I, Kikuchi H, Ikada $\mathrm{Y}$, Iwata $\mathrm{H}$, Yamamoto K. Development of a dural substitute from synthetic bioabsorbable polymers. J Neurosurg 1997;86:1012-1017.

6. Anson JA, Marchand EP. Bovine pericardium for dural grafts: Clinical results in 35 patients. Neurosurgery 1996;39:764-768.

7. Filippi R, Derdilopoulos A, Heimann A, Krummenauer F, Perneczky A, Kempski O. Tightness of duraplasty in rabbits: A comparative study. Neurosurgery 2000;46:1470-1476.

8. Mello LR, Feltrin LT, Fontes Neto PT, Ferraz FA. Duraplasty with biosynthetic cellulose: An experimental study. J Neurosurg 1997; 86:143-150.

9. Parizek J, Husek Z, Mericka P, Tera J, Nemecek S, Spacek J, Nemeckova J, Suba P. Ovine pericardium: A new material for duraplasty. J Neurosurg 1996;84:508-513.

10. Robertson JT, Soble-Smith J, Powers N, Nelson PA. Prevention of cerebrospinal fistulae and reduction of epidural scar with new surgical hemostat device in a porcine laminectomy model. Spine 2003;28:2298-2303.

11. Stern WE. The surgical application of freeze-dried homologous dura mater. Surg Gynecol Obstet 1958;106:159-162.

12. Warren WL, Medary MB, Dureza CD, Bellotte JB, Flannagan PP, Oh MY, Fukushima T. Dural repair using acellular human dermis: Experience with 200 cases: Technique assessment. Neurosurgery 2000;46:1391-1396.

13. Cain JE Jr, Dryer RF, Barton BR. Evaluation of dural closure techniques. Suture methods, fibrin adhesive sealant, and cyanoacrylate polymer. Spine 1988;13:720-725.

14. Cain JE Jr, Rosenthal HG, Broom MJ, Jauch EC, Borek DA, Jacobs RR. Quantification of leakage pressures after durotomy repairs in the canine. Spine 1990;15:969-970.

15. Preul MC, Bichard WD, Spetzler RF. Toward optimal tissue sealants for neurosurgery: Use of a novel hydrogel sealant in a canine durotomy repair model. Neurosurgery 2003;53:1189-1198.

16. Czosnyka $M$, Balestreri $M$, Steiner $L$, Smielewski $P$, Hutchinson PJ, Matta B, Pickard JD. Age, intracranial pressure, autoregulation, and outcome after brain trauma. J Neurosurg 2005;102: 450-454.

17. Freeman L. The use of egg-membrane in trephining operations upon the skull. Ann Surg 1898;28:455-457.

18. Pudenz RGO. Meningocerebral adhesions: An experimental study of the effect of human amniotic membrane, amnioplastin, beef allantoic membrane, cargile membrane, tantalum foil, and polyvinyl alcohol films. Surgery 1942;12:318-344.

19. Schlag MG, Hopf $R$, Redl $H$. Convulsive seizures following subdural application of fibrin sealant containing tranexamic acid in a rat model. Neurosurgery 2000;47:1463-1467.

20. Robertson SC, Menezes AH. Hemorrhagic complications in association with silastic dural substitute: Pediatric and adult case reports with a review of the literature. Neurosurgery 1997;40:201-205.

21. Thadani V, Penar PL, Partington J, Kalb R, Janssen R, Schonberger LB, Rabkin CS, Prichard JW. Creutzfeldt-Jakob disease probably acquired from a cadaveric dura mater graft. Case report. J Neurosurg 1988;69:766-769.

22. Budka H, Aguzzi A, Brown P, Brucher JM, Bugiani O, Collinge J, Diringer H, Gullotta F, Haltia M, Hauw JJ. Tissue handling in suspected Creutzfeldt-Jakob disease (CJD) and other human spongiform encephalopathies (prion diseases). Brain Pathol 1995;5: 319-322.

23. Alleyene $\mathrm{CH}$ Jr, Cawley $\mathrm{CM}$, Barrow DL, Poff $\mathrm{BC}$, Powell MD, Sawhney AS, Dillehay DL. Efficacy and biocompatibility of a photopolymerized, synthetic, absorbable hydrogel as a dural sealant in a canine craniotomy model. J Neurosurg 1998;88:308-313.

24. Preul MC, Campbell PK, Bichard WD, Spetzler RF. Application of a hydrogel sealant improves watertight closures of duraplasty onlay grafts in a canine craniotomy model. J Neurosurg 2007;107: 642-650.

25. Becker TA, Kipke DR. ALGEL ${ }^{\circledR}$ as a Dural Sealant: Determination of Effects on the Sensori-Motor Cortex in Rats. Mexico: Cancun; 2003.

26. Vetter RJ, Becker TA, Williams JC, Kipke DR. The Use of ALGEL as an Artificial Dura for Chronic Cortical Implant Neuroprosthetics. Italy: Capri Island; 2003. 
27. Becker TA, Kipke DR, Preul MC, Bichard W, McDougall CG. In vivo assessment of calcium alginate gel for endovascular embolization of a cerebral arteriovenous malformation model using the swine rete mirabile. Neurosurgery 2002;51:453-458.

28. Becker TA, Kipke DR, Brandon T. Calcium alginate gel: A biocompatible and mechanically stable polymer for endovascular embolization. J Biomed Mater Res 2001;54:76-86.

29. Draget KI, SkjakBraek G, Smidsrod O. Alginate based new materials. Int J Biol Macromol 1997;21:47-55.

30. Becker TA, Preul MC, Bichard WD, Kipke DR, McDougall CG. Calcium alginate gel as a biocompatible material for endovascula arteriovenous malformation embolization: Six-month results in an animal model. Neurosurgery 2005;56:793-801.

31. Agarwal A, Varma A, Sarkar C. Histopathological changes following the use of biological and synthetic glue for dural grafts: An experimental study. Br J Neurosurg 1998;12:213-216.

32. Schwartz FT, Sartawi MA, Fox JL. Unusual hematomas outside the spinal cord. Report of two cases. J Neurosurg 1973;39: 249-251.

33. Cui X, Wiler J, Dzaman M, Altschuler RA, Martin DC. In vivo studies of polypyrrole/peptide coated neural probes. Biomaterials 2003;24:777-787.

34. Mickey BJ, Middlebrooks JC. Representation of auditory space by cortical neurons in awake cats. J Neurosci 2003;23:86498663.

35. Arieli A, Grinvald A, Slovin H. Dural substitute for long-term imaging of cortical activity in behaving monkeys and its clinical implications. J Neurosci Methods 2002;114:119-133.

36. Rousche PJ, Pellinen DS, Pivin DP Jr, Williams JC, Vetter RJ, Kipke DR. Flexible polyimide-based intracortical electrode arrays with bioactive capability. IEEE Trans Biomed Eng 2001;48: 361-371.

37. Williams JC, Rennaker RL, Kipke DR. Long-term neural recording characteristics of wire microelectrode arrays implanted in cerebral cortex. Brain Res Brain Res Protoc 1999;4:303-313.

38. Ohbayashi N, Inagawa T, Katoh Y, Kumano K, Nagasako R, Hada $\mathrm{H}$. Complication of silastic dural substitute 20 years after dural plasty. Surg Neurol 1994:41:338-341.
39. Ekseth K, Bostrom S. Late complications of Silastic duraplasty: Low-virulence infections. Case report. J Neurosurg 1999;90:559562.

40. Maynard EM, Fernandez E, Normann RA. A technique to prevent dural adhesions to chronically implanted microelectrode arrays. J Neurosci Methods 2000;97:93-101.

41. Nunamaker EA, Otto KJ, Kipke DR. Investigation of the material properties of alginate for the development of hydrogel repair of dura mater. J Mech Behav Biomed Mater 2010, doi:10.1016/j.jmbbm. 2010.08.006.

42. Vetter RJ, Williams JC, Hetke JF, Nunamaker EA, Kipke DR. Chronic neural recording using silicon-substrate microelectrode arrays implanted in cerebral cortex. IEEE Trans Biomed Eng 2004; 51:896-904.

43. Schmidt EM, Bak MJ, Mclntosh JS. Long-term chronic recording from cortical neurons. Exp Neurol 1976;52:496-506.

44. Yuen TG, Agnew WF, Bullara LA. Tissue response to potential neuroprosthetic materials implanted subdurally. Biomaterials 1987;8:138-141.

45. Choudhari KA. 'In-lay' duraplasty: A useful method of effective dural closure. Br J Neurosurg 2001;15:533-535.

46. Artru AA, Momota $Y$. Rate of CSF formation and resistance to reabsorption of CSF during sevoflurane or remifentanil in rabbits. J Neurosurg Anesthesiol 2000;12:37-43.

47. Wilson FA, Ryou JW, Kim BH, Greenberg PA. Amelioration of dural granulation tissue growth for primate neurophysiology. J Neurosci Methods 2005;144:203-205.

48. Hammerle $\mathrm{CH}$, Schmid J, Lang NP, Olah AJ. Temporal dynamics of healing in rabbit cranial defects using guided bone regeneration. J Oral Maxillofac Surg 1995;53:167-174.

49. Hopper RA, Zhang JR, Fourasier VL, Morova-Protzner I, Protzner $\mathrm{KF}$, Pang $\mathrm{CY}$, Forrest $\mathrm{CR}$. Effect of isolation of periosteum and dura on the healing of rabbit calvarial inlay bone grafts. Plast Reconstr Surg 2001;107:454-462.

50. Ratner BD. Biomaterials Science: An Introduction to Materials in Medicine. San Diego: Academic Press; 1996. 484 p.

51. Kim YT, Hitchcock RW, Bridge MJ, Tresco PA. Chronic response of adult rat brain tissue to implants anchored to the skull. Biomaterials 2004;25:2229-2237. 